\title{
Acquired Factor V Inhibitors: A Review of Literature
}

\author{
Boland $\mathrm{F}^{1 *}$ and Shreenivas $\mathrm{AV}^{2}$ \\ ${ }^{1}$ Department of Medicine, Icahn School of Medicine, New \\ York \\ ${ }^{2}$ Division of Hematology-Oncology, Icahn School of \\ Medicine, USA \\ *Corresponding author: Boland F, Department of \\ Medicine, Icahn School of Medicine, Mount Sinai St. \\ Luke's and Mount Sinai West, New York
}

Received: J une 20, 2017; Accepted: August 08, 2017;

Published: August 30, 2017

\section{Abstract}

Objective: The implications of inhibitor formation can vary from an asymptomatic prolonged APTT and PT to a life threatening hemorrhage. We are still trying to understand why there are such variable clinical phenotypes and how we might best risk stratify patients. The focus of this review is to dissect the literature on this topic and offer recommendations to managing this rare affliction in the clinical setting.

Evidence Review: We conducted a search on PubMed, Scopus, web of science from 2010 until 2016 using different combinations of the following terms "factor V inhibitors", "factor V autoantibodies", "FV inhibitors", "Factor V and spontaneous inhibitors". We cross referenced the bibliographies for additional reports. 47 cases were included in final review.

Findings: The most common bleeding presentations included hematuria $23 \%(n=11)$ and gastrointestinal bleed $21 \%(n=10) .23 \%(n=11)$ of patients were asymptomatic at the time of presentation. $34 \%$ of cases were associated with infection and $31 \%$ with drugs. The median inhibitor titer and FVa (Factor $\mathrm{V}$ activity) was 9 Bethesda units and $2 \%$ respectively. The median PT and aPTT at presentation was 50 and 100 seconds respectively. To eliminate the inhibitor, steroids were generally used a first line therapy. 88\% who received steroids alone for immunosuppression achieved remission. Other agents used included rituximab, IVIG, plasmapheresis, thalidomide and cyclophosphamide. The time for inhibitor disappearance was documented in 22 cases with a median time of 3.5 weeks.

Conclusion: Diagnosis and treatment of factor $\mathrm{V}$ inhibitors remains a challenge for clinicians. Because of its rare presentation and expertise required in diagnosing this disorder at present there are no trials to compare treatment options to analyze both acute bleeding control and inhibitor eradication.

Keywords: Factor V inhibitors; Factor V deficiency

\section{Introduction}

Factor $\mathrm{V}$ inhibitor is one of the rare forms of factor inhibitors and is an infrequent cause of factor $\mathrm{V}$ deficiency. Factor $\mathrm{V}$ is an integral part of the coagulation cascade. Synthesized in the liver, it acts as a cofactor in the prothrombinase complex. It is cleaved by thrombin into a 2-chain molecule and serves to activate prothrombin. It also has important anticoagulant properties by participating in the inactivation of factor VIII (FVIII). The first case was documented in 1955 in Germany [1]. The development of inhibitors against Factor V is an extremely rare occurrence with an estimated incidence of 0.09 0.023 for 1 million persons per year, based on studies in Singapore and Australia [2]. There are five incidences when FV inhibitors develop: following exposure to bovine proteins, post-operatively in those not exposed to bovine proteins, inhibitors associated with other medical conditions, in congenital factor deficiency after replacement therapy and idiopathic formation of FVI. Historically FVI occurred most commonly due to bovine proteins. During surgical procedures topical bovine preparations were often used. This initiated the production of autoantibodies against bovine proteins including bovine FV which cross reacted with human FV. Though bovine thrombin has since been replaced by human and recombinant thrombin formulation which exhibit less antigenicity, there is still an association with surgical procedures and the formation of autoantibodies against FV. This may be due to prior exposure to bovine proteins causing a low titer of these antibodies which may then be stimulated by human or recombinant thrombin. Although 3 mechanisms, namely spontaneous autoantibodies, alloantibodies, and cross-reacting anti bovine factor $\mathrm{V}$ antibodies, have been hypothesized, the precise mechanisms of inhibitor development remain unknown. Normally, factor V acts by binding to the procoagulant phospholipid -phosphatidylserine -on activated platelets and endothelial cells through its C2 domain of its light chain. This complex binds to von Willebrand factor and enhances the coagulation process by acting as a cofactor to activated factor $\mathrm{X}$, which cleaves prothrombin to thrombin. Factor $\mathrm{V}$ inhibitors are polyclonal IgG antibodies that attack the C2 domain of light chain of factor $\mathrm{V}$ resulting in loss of function, by decreasing the procoagulation effect of factor $\mathrm{V}$ [3].

\section{Purpose of study}

The implications of inhibitor formation can vary from an asymptomatic prolonged APTT and PT to a life threatening hemorrhage. We are still trying to understand why there are such variable clinical phenotypes and how we might best risk stratify patients. Therefore, the recognition, work up, diagnostics and management of this condition is of extreme importance. The focus 
Table 1: Case reports of Acquired Factor $V$ inhibitors.

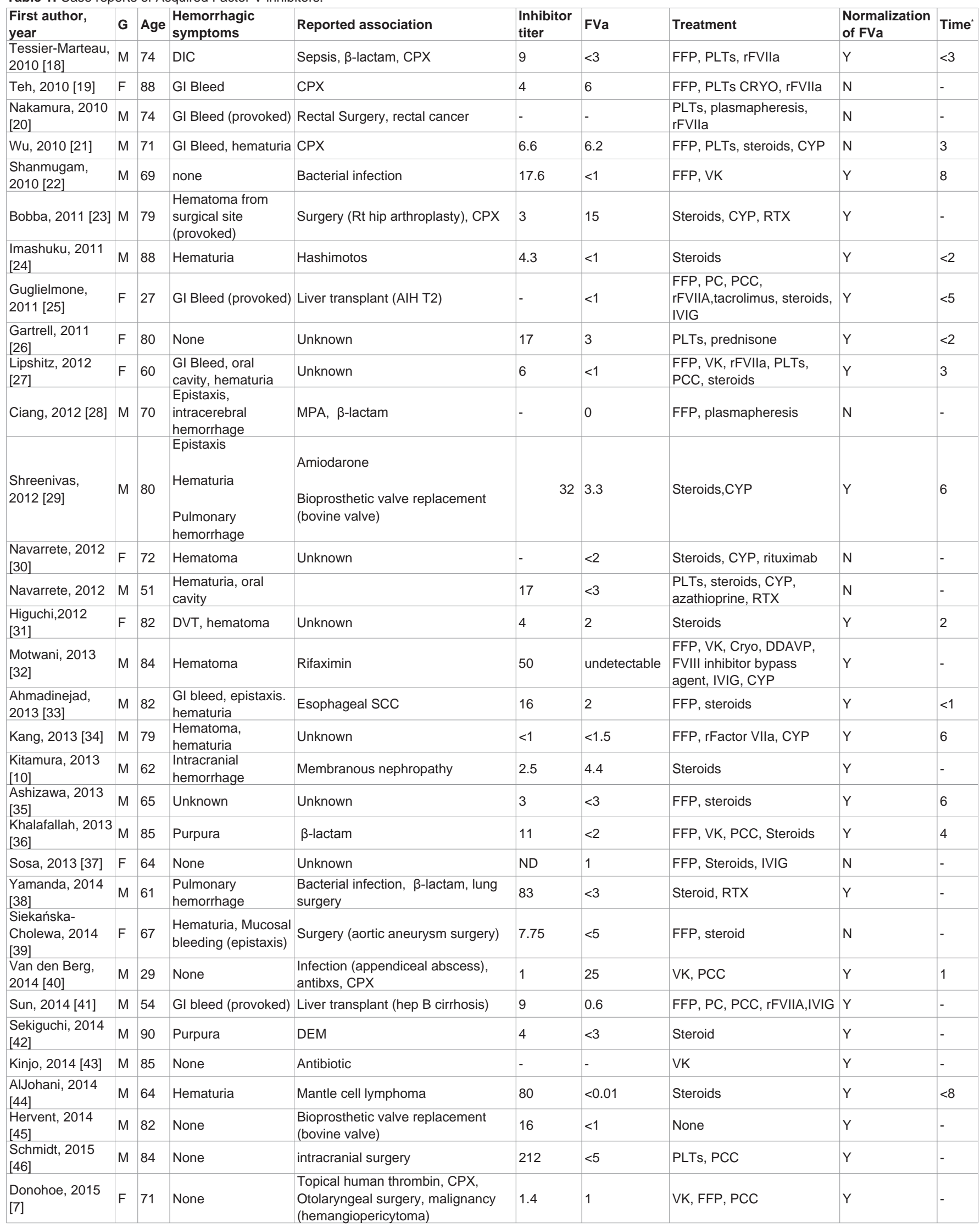




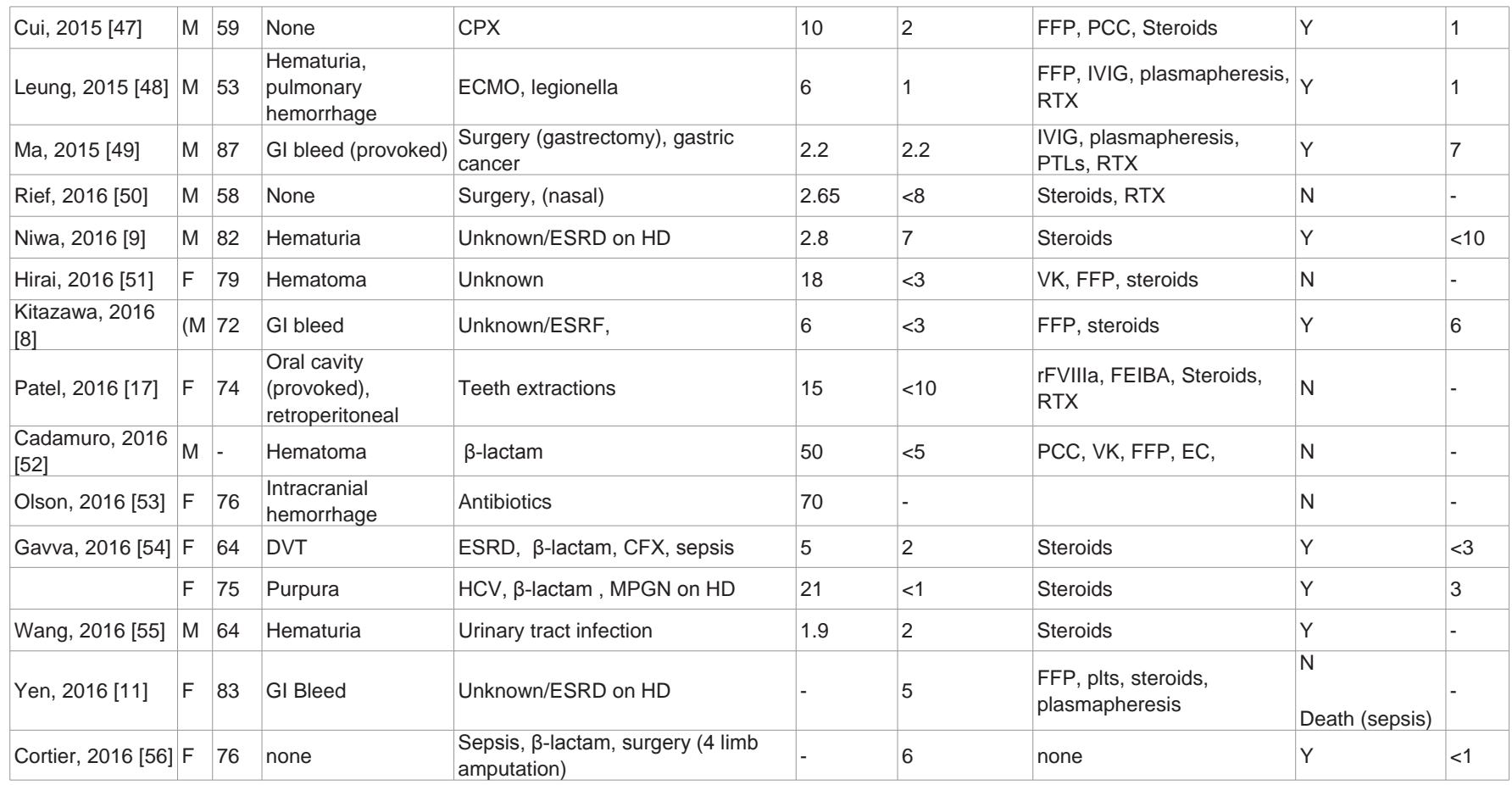

"Time to inhibitor disappearance (wks); G: Gender; MPA: Microscopic polyangiitis; CFX: Ciprofloxacin; CPX: Cephalosporin; ECMO: Extracorporeal Membrane Oxygenation; ESRF: End Stage Renal Failure; DEM: Dabigatran Etexilate Methanesulfonate; CRYO: Cryoprecipitate; FFP: Fresh Frozen Plasma; PLTs: Platelets: VK: Vitamin K; PCC: Prothrombin Complex Concentrate; EC: Erythrocyte Concentrate; rFVIla: Recombinant Factor VIIa; RTX: Rituximab; CYP: Cyclophosphamide; AIH T2: Autoimmune Hepatitis Type 2; SCC: Squamous Cell Carcinoma; FEIBA: Factor VIII Inhibitor bypass Activity; ND: Not detected

Table 2: Etiology implicated

\begin{tabular}{|l|l|}
\hline Reported Association* & Number of cases (\%) \\
\hline Infection & $16(34)$ \\
\hline Surgery & $12(25)$ \\
\hline Antibiotics & $15(31)$ \\
B-lactam & $8(17)$ \\
Cephalosporin & $6(13)$ \\
Not specified & $4(8)$ \\
\hline Malignancy & $4(8)$ \\
\hline Autoimmune disorder & $3(6)$ \\
\hline Unknown & $12(25)$ \\
\hline
\end{tabular}

*several pts with more than one association

"some patients receiving both $\beta$-lactams and cephalosporins

of this review is to dissect the literature on this topic and offer recommendations to managing this rare affliction in the clinical setting.

\section{Search methods}

To focus this review specifically on inhibitors to FV, we examined the literature for recent review articles on this topic. A comprehensive systematic review on acquired factor $\mathrm{V}$ inhibitors was carried out by Franchini and Lippi in 2011 which analyzed data from 74 cases up to 2010. To avoid redundancy, we conducted a search on PubMed, Scopus, Web of Science from 2010 until 2016 using different combinations of the following terms "factor V inhibitors", "factor $\mathrm{V}$ autoantibodies", "FV inhibitors", "Factor V and spontaneous inhibitors". We cross referenced the bibliographies for additional reports. Only articles in English were included.
Table 3: Hemorrhagic manifestations at presentation.

\begin{tabular}{|c|c|}
\hline Bleeding site & N (\%) \\
\hline $\begin{array}{l}\text { Mucosal } \\
\text { Gastrointestinal } \\
\text { Genitourinary } \\
\text { Upper airway/oral cavity }\end{array}$ & $\begin{array}{l}10(21) \\
12(25) \\
3(6)\end{array}$ \\
\hline Intracerebral & $3(6)$ \\
\hline Hematoma & 7 (14) \\
\hline Skin & $3(6)$ \\
\hline Lungs & $3(6)$ \\
\hline Asymptomatic & $11(23)$ \\
\hline
\end{tabular}

\section{Literature Results and Discussion}

94 cases of AFVD were documented in the literature. As illustrated in Figure 1, 47 cases were excluded. Cases in which inhibitors formed secondary to bovine thrombin were excluded given this less clinically relevant. A case series conducted by the Mayo clinic in which patients with MPN (myeloproliferative neoplasm) were found to have low levels of Factor V was excluded given there were no inhibitors detected, though it was noted that 3 out of the 33 patients did have clotting studies suggestive of an inhibitor though none was detected, which was also discovered in 2 of our case reports [4]. This is an interesting caveat when establishing a diagnosis of acquired factor $\mathrm{V}$ deficiency due to an inhibitor, which we shall discuss further on. An additional 2 cases were associated with congenital factor $\mathrm{V}$ deficiency which was excluded given the different mechanism of action of inhibitors in this setting. These patients given their history of bleeding disorder undergo a different specialized approach which will not be 
Table 4: Analysis of asymptomatic patients $(\mathrm{N}=11)$.

\begin{tabular}{|l|l|l|l|l|l|}
\hline Suspected Etiology & Inhibitor Titre (BU) & FVa & APTT & PT/INR & Outcomel (time to inhibitor disappearance in wks) \\
\hline infection & 17.6 & $<1$ & 48.7 & & Remission (8w) \\
\hline unknown & 17 & 3 & 150 & $54.6 / 5.8$ & Death $2 / 2$ sepsis \\
\hline unknown & not detected & 1 & 94.4 & 36 & Persistent (no inhibitor found) \\
\hline infection, CPX & 1 & 25 & 38.3 & 25.8 & Spontaneous resolution (1wk) \\
\hline antibiotics & - & - & - & - & Remission \\
\hline bioprosthetic valve replacement (bovine valve) & 16 & $<1$ & 141 & - & Death $2 / 2$ renal failure \\
\hline intracranial surgery & 212 & $<5$ & - & - & Remission \\
\hline $\begin{array}{l}\text { topical human thrombin, antibiotics, surgery, } \\
\text { malignancy }\end{array}$ & 1.4 & 1 & 49.5 & 14.9 & Remission \\
\hline CPX & 10 & 2 & 200 & 68.3 & Remission (1w) \\
\hline surgery & 2.65 & $<8$ & 67.7 & 37 & Persistent \\
\hline infection, $\beta$-lactam, surgery & - & 6 & 72 & 24.9 & Remission (<1wk) \\
\hline
\end{tabular}

Table 5: Death secondary to hemorrhage, $\mathrm{N}=7$.

\begin{tabular}{|c|c|c|c|c|c|c|c|}
\hline Bleeding site & Suspected Etiology & Inhibitor Titre (BU) & $\mathrm{FVa}$ & APTT & PT/INR & Treatment & Site of fatal hemorrhage \\
\hline GI & $\mathrm{CPX}$ & 4 & 6 & 173 & $50.7 /-$ & $\begin{array}{l}\text { FFP, PLTs CRYO, } \\
\text { rFVIla }\end{array}$ & Gastrointestinal \\
\hline GI Bleed, hematuria & CPX & 6.6 & 6.2 & 100 & $50 /-$ & $\begin{array}{l}\text { FFP, PLTs, steroids, } \\
\text { CYP }\end{array}$ & Gastrointestinal \\
\hline $\begin{array}{l}\text { Epistaxis, intracerebral } \\
\text { hemorrhage, }\end{array}$ & MPA, $\beta$-lactam & - & - & 120 & $-/ 8$ & FFP, plasmapheresis & Intracerebral \\
\hline Hematuria, epistaxis & $\begin{array}{l}\text { Surgery (aortic aneurysm } \\
\text { surgery) }\end{array}$ & 7.75 & $<5$ & - & - & FFP, steroids & Intracerebral \\
\hline Hematoma & Unknown & 18 & $<3$ & 120 & $60 /-$ & VK, FFP, steroids & Intracerebral \\
\hline Hematoma & $\beta$-lactam & 50 & $<5$ & 150 & $-/ 5.7$ & PCC, VK, FFP, EC & Not specified \\
\hline Intracranial hemorrhage & Antibiotics & 70 & - & 160 & $59.1 /-$ & & Intracerebral \\
\hline
\end{tabular}

discussed in this review. The 47 remaining cases were reviewed which is outlined in Table 1.

\section{Demographics and etiology}

Of the 47 cases analyzed, 31 (66\%) were male and 16 (34\%) female. The median age was 74 years (range 29-90). The predisposition towards males and the broad age range is in keeping with a review carried out by [6] Ang, et al. in 2009 and signifies the need to be aware of this condition developing in any patient presenting with a bleeding diathesis. With this rare condition we rely heavily on the data from case reports to guide us to the causation behind these inhibitors. Over 200 case reports have been documented based on this review and in the literature $[5,6]$. The associations implicated in our review are noted in Table 2. Surgical procedures were associated with $22 \%$ of cases. For some patients it is not clear if they had been exposed to bovine thrombin in the past. One such case postulates that prior formed antibodies from bovine thrombin from a previous surgery were stimulated by exposure to human thrombin [7]. The majority of patients that underwent a surgical procedure also had other possible causations such as underlying malignancy or autoimmune disorder or concurrent antibiotic use perioperatively. This of course makes the association extremely difficult to establish. Likewise, infection (bacterial or viral), was an associated etiology in $34 \%$, however $17 \%$ had also received antibiotics prior to discovery of the FVI. In fact, $30 \%$ of patients had more than one associated condition or drug. A large proportion of cases were found to have no underlying trigger. In this review this was the case for $25 \%$ of patients. This may be partly due to inability to uncover an underlying pathology or establish causation. In 2 cases there is a noted association with eosinophilia, renal failure and FV inhibitors suggesting an underlying immunoallergic process $[8,10]$. It is also observed that 2 cases where no causation is found, both patients were undergoing hemodialysis $[9,11]$. However, again causation is difficult to prove and it is hard to confirm that these patients did not have an underlying autoimmune disease or were exposed to a medication not commonly known to trigger autoantibody production. When combining this review with that of Franchini's [5], the most common causation is antibiotics which was associated with $38 \%$ of cases $(48 / 125)$. Next most common are surgery followed by infection at $29 \%$ and $27 \%$ respectively.

\section{Clinical presentations and laboratory results}

The most common bleeding presentations as highlighted in Table 2 included hematuria $(n=11)$, gastrointestinal bleed $(n=10)$ and hematoma $(\mathrm{n}=7)$ and least common was intracranial hemorrhage $(n=3)$ and pulmonary hemorrhage $(n=2) .23 \%(n=11)$ of patients were asymptomatic. Given Factor V participates in both procoagulant and anticoagulant pathways, it is not surprising that thrombosis occurred in some of patients $(n=3)$. The laboratory findings were extremely variable, though of course, all documented cases were consistent with having a prolonged PT and aPTT. On mixing studies, $91 \%$ of cases were not fully correctable on 1:1 mixing studies with pooled normal plasma. The four cases that fully corrected, represents a rare entity which contradicts the basic principle that we use to work up these abnormal coagulation studies. In one such case by Lipshitz [24], the patient has a proven factor inhibitor, despite mixing studies showing complete correction. In this case, it is hypothesized 
that factor $\mathrm{V}$ inhibition may be time dependent. Another such case, [34] demonstrated another diagnostic dilemma, in that no inhibitor was found, yet it also seemed that this was not a production problem. It was suggested, there may be an antibody present which is escaping detection by ELISA and rapidly removing FV without the selective binding of FV to tissues or neutralizing its activity. A case documented in 2014, was unable to confirm the presence of an inhibitor but did notice a pattern consistent with phospholipid dependence but most significantly affecting FV [40]. This is due to either FV in the presence of lupus anticoagulant (LA), or a FV with phospholipid dependence, or may have been a LA with more pronounced factor $\mathrm{V}$ inhibition. With the potential for these unusual laboratory findings, clinicians need to be persistent with a thorough investigation to prove evidence of FV inhibitors. Though the PT and PTT were consistently prolonged, these values were extremely variable, with a median PT and APTT at presentation of 50 and 100 seconds respectively. A wide range of inhibitor titres and Factor $\mathrm{V}$ activity was also notable. The median inhibitor titer and FVa (Factor $\mathrm{V}$ activity) was 9 Bethesda units and 2\% respectively. In contrast with other coagulation factor inhibitors, the level of factor $\mathrm{V}$ inhibitors does not correlate with the degree of clinical bleeding. In addition, the risk of bleeding does not seem to correlate with prolongation of prothrombin time or activated partial thromboplastin time, factor $\mathrm{V}$ activity, factor $\mathrm{V}$ inhibitor levels, or the duration of presence of factor $\mathrm{V}$ inhibitor. This brings up two relevant questions. Firstly, that the incidence of FVI is likely underestimated given almost 1 in 4 of the patients were asymptomatic. This is similar to the review by [6] Ang, et al. where $32 \%$ of cases demonstrated no bleeding. Analyzing the coagulation profiles and FVa (Factor V activity) in the asymptomatic patients (Table 4) and those who experienced fatal hemorrhage (Table 5) showed no apparent association between FVa, inhibitor titer and derangement of aPTT and PTT. This makes the approach to the asymptomatic population trickier as it is unpredictable which patients may be at higher risk of a bleeding event.

\section{Outcomes}

The mainstay of treatment focuses on bleeding control with replacement products and attempting to eradicate inhibitors using immunosuppressive therapies. As we alluded to, the bleeding risk is highly variable with poor correlation to coagulation studies making this a challenging disease to manage. For bleeding control fresh-frozen plasma, platelet transfusions, prothrombin complex concentrates can achieve hemostasis. There is growing evidence that platelet transfusions should be used first line to control acute bleeding episodes. $20 \%$ of our factor V is stored in platelets and this FV seems to have different properties that allows it to escape FV inhibitors $[12,13]$. There is also evidence to suggest functionally distinct features of platelet and plasma FV $[14,15]$. One small study showed that patients with severe congenital FV with undetectable plasma FV had functional FV in their platelets [6]. Ang, et al, demonstrated control of bleeding using platelet concentrates (PC) in almost $70 \%$ of patients $(11 / 16)$. In this review, $58 \%(7 / 12)$ of cases resulted in normalization of FV with use of PC. It is thought that the use of prothrombin concentrates and fresh frozen plasma has a limited role given their low concentrations of FV. However, for unclear reasons, recombinant FVIIa seems to aid in hemostasis despite its dependence on FV for its mechanism of action. It is possible that FVIIa may utilise platelet FV and may be used as an adjunct to platelet transfusions. In addition to hemostasis, management involves inhibitor elimination. Most cases documented a good response to steroids which is generally the first line approach. $88 \%$ who received steroids alone for immunosuppression achieved remission. Other agents used include rituximab, IVIG, plasmapheresis, thalidomide and cyclophosphamide. As these agents were often used in combination it is problematic to dissect which treatment proved successful. $69 \%$ had normalization of their FVa which in the majority of cases did correlate with inhibitor disappearance. The time for inhibitor disappearance was documented in 22 cases with a median time of 3.5 weeks. Given the success rate with steroids alone this is a reasonable first line treatment. In some cases, where patients have recurrence of the inhibitor, rituximab has been used as maintenance treatment with good results [14]. 60\% of asymptomatic patients in this cohort had remission of the inhibitor. Though inhibitor persistence occurred in $20 \%$ of asymptomatic patients, there were no bleeding complications. This is in keeping with general recommendations to manage asymptomatic patients conversationally. There is no indication to eradicate the inhibitor in asymptomatic given the majority will resolve spontaneously.

\section{Conclusion}

Diagnosis and treatment of factor $\mathrm{V}$ inhibitors remains a challenge for clinicians. Exact pathophysiology of factor $\mathrm{V}$ inhibitor formation remains unknown. Until this mechanism is better understood we will be unable to appropriately screen for this disease. Similarly, because of its rare presentation and expertise required in diagnosing this disorder, at present there are no trials to compare treatment options to analyze both acute bleeding control and inhibitor eradication. Physicians will have to be more cognizant regarding patients presenting with unprovoked bleeding in the setting of abnormal coagulation profile, this will help identify more cases and allow prompt treatment.

\section{References}

1. aHORDER MH. Isolierter Factor $\mathrm{V}$-Mangel bedingt durch einen spezifischen Hemmko"rper. Acta Haematologica. 1955; 13: 235-241.

2. Department of Statistics, Ministry of Trade and Industry, Singapore. The Yearbook of Statistics Singapore, 2007. Singapore: Department of Statistics; 2007. 2016.

3. Ortel TL, Moore KD, Quinn-Allen MA, Okamura T, Sinclair AJ, Lazarchick J. Inhibitory antifactor $\mathrm{V}$ antibodies bind to the factor $\mathrm{V} \mathrm{C} 2$ domain and are associated with hemorrhagic manifestations. Blood. 1998; 91: 4188-4196.

4. Ashrani AA, Tefferi A, Pruthi R K, Pardanani A. Acquired factor V deficiency in myeloproliferative neoplasms: a Mayo Clinic series of 33 patients. British Journal of Haematology. 2015; 171: 5 875-5879.

5. Franchini M, Lippi G. Acquired factor $\mathrm{V}$ inhibitors: a systematic review. J Thromb Thrombolysis. 2011; 31: 449-457.

6. Ang $\mathrm{AL}$, Kuperan $\mathrm{P}, \mathrm{Ng} \mathrm{CH}, \mathrm{Ng} \mathrm{H}$ J. Acquired factor $\mathrm{V}$ inhibitor. A problembased systematic review. Thrombosis and Haemostasis. 2009; 101: 52-59.

7. Donohoe $\mathrm{K}$, Levine R. Acquired factor $\mathrm{V}$ inhibitor after exposure to topical human thrombin related to an otorhinolaryngological procedure. Journal of Thrombosis and Haemostasis. 2015; 13: 1787-1789.

8. Kitazawa A, Misawa H, Nagahori K, Koda R, Yoshino A, Kawamoto S, et al. Acquired factor $\mathrm{V}$ inhibitors in a patient with end-stage renal disease. Internal Medicine. 2016; 55: 3505-3509.

9. Niwa N, Yoshida T, Mizuno R, Oya M, Hayashi M. Renal hemorrhage caused by acquired inhibitors to coagulation factors VIII and $\mathrm{V}$ in a hemodialysis patient. Cen Case Reports. 2016; 5: 223-226. 
10. Kitamura S, Misawa M, Namba S, Tsuji K, Torigoe R, Shima M, et al Membranous nephropathy with acquired factor $V$ inhibitor: a case report. BMC Res Notes. 2013; 6: 553.

11. Yen CC, Cho SF, Huang DY, Chen HC, Huang DY. Rare case report: Acquired factor $v$ deficiency with an idiopathic inhibitor. Journal of Internal Medicine of Taiwan. 2016; 27: 97-102.

12. Perdekamp MT, Rubenstein DA, Jesty J, Hultin MB. Platelet factor V supports hemostasis in a patient with an acquired factor $\mathrm{V}$ inhibitor, as shown by prothrombinase and tenase assays. Blood Coagul Fibrinolysis. 2006; 17: 593-597.

13. Chediak J, Ashenhurst JB, Garlick I, Desser RK. Successful management of bleeding in a patient with factor $\mathrm{V}$ inhibitor by platelet transfusions. Blood. 1980; 56: 835-841.

14. Gould WR, Silveira JR, Tracy PB. Unique in vivo modifications of coagulation factor $\mathrm{V}$ produce a physically and functionally distinct platelet-derived cofactor: characterization of purified platelet-derived factor $\mathrm{V} / \mathrm{Va}$. J Biol Chem. 2004; 279: 2383-2393.

15. Gould WR, Simioni P, Silveira JR, Tormene DM, Kalafatis PB, Tracy Megakaryocytes endocytose and subsequently modify human factor $\mathrm{V}$ in vivo to form the entire pool of a unique platelet-derived cofactor. J Thromb Haemost. 2005; 3: 450-456.

16. Duckers C, Simioni P, Spiezia L, Radu C, Dabrilli P, Gavasso S et al. Residual platelet factor $V$ ensures thrombin generation in patients with severe congenital factor $V$ deficiency and mild bleeding symptoms. Blood. 2010; 115 : 879-886

17. Patel MD, Hajdenberg J. Successful treatment of chronic recurrent lifethreatening bleeding due to an acquired factor $\mathrm{V}$ Inhibitor with rituximab and steroids. Haemophilia. 2016; 22: 3.

18. Tessier-Marteau A, Croquefer S, Meziani F, Cau S, Asfar P, Macchi L. Acquired factor $V$ inhibitor in a context of sepsis and disseminated intravascular coagulation. American Journal of Hematology. 2010; 85: 145 146

19. Teh PP, Grigoriadis G, Salem H. Acquired factor $\mathrm{V}$ inhibitor. Intern Med J. 2010; 40: 667-668

20. Nakamura T, Otsuji M, Kurita A, Yamada K, Tsubokawa T, Yamamoto K [Anesthetic management of a patient with acquired factor $V$ inhibitor]. Masui. 2010; 59: 1423-1427.

21. Wu MT, Pei SN. Development of cephradine-induced acquired factor $V$ inhibitors: a case report. Ann Pharmacother. 2010; 44: 1673-1676.

22. Shanmugam H, Jayaranee S, Eow GI. A case report of an acquired inhibitor to coagulation factor V. Haemophilia. 2011; 17: 1

23. Bobba RK, Garg P, Arya M, Freter CE. Postoperative Bleeding in an Elderly Patient from Acquired Factor $V$ Inhibitor: Rapid Response to Immunosuppressive Therapy. The American Journal of the Medical Sciences. 2011; 341: 253-256.

24. Imashuku S, Hasegawa S, Kubo S, Nakato S, Shima S. Anti-Factor V inhibitor in patients with autoimmune diseases: case report and literature review. International Medical Case Reports Journal. 2011; 31

25. Guglielmone H, Jarchum G, Minoldo S. Successful treatment with intravenous immunoglobulin (IVIg) in a patient with an acquired factor $\mathrm{V}$ inhibitor after liver transplantation. Thromb Haemost. 2011; 106: 985-986.

26. Gartrell B. Acquired factor $\mathrm{V}$ inhibitor complicating warfarin therapy. Am J Hematol. 2011; 86: 710-712.

27. Lipshitz J, Chelliah T, Aledort L. A case of factor $V$ inhibitor with complete correction of the PT and aPTT upon mixing. Am J Hematol. 2012; 87: 313 315.

28. Ciang $\mathrm{CO}$, Leung $\mathrm{MH}$. Acquired factor $\mathrm{V}$ inhibitor in systemic vasculitis International Journal of Rheumatic Diseases. 2012; 15: 19-22.

29. Shreenivas AV, Lipshitz J, Patel D. A rare case of factor $V$ inhibitor in a patien on amiodarone therapy. Blood Coagulation \& Fibrinolysis. 2012; 23: 342-344.
30. Navarrete MA, van der Meer FJ, Damiani G, Diaz A, Eikenboom J. The use of rituximab therapy in patients with acquired factor $V$ inhibitors. Am J Hematol. 2012; 87: 826-827.

31. Higuchi T, Okamoto T, Kou T, Takeuchi T, Koyamada R, Okada S. Deep vein thrombosis associated with factor $\mathrm{V}$ inhibitor followed by immune thrombocytopenia. Ann Hematol. 2012; 91: 1831-1832.

32. Motwani P, Howard L, Ali SS. Successful Management of a Possible Antibiotic-Related Acquired Factor V Inhibitor: A Case Report and Review of the Literature. Acta Haematologica. 2013; 129: 182-184.

33. Ahmadinejad $\mathrm{M}$, Roushan N. Acquired factor $\mathrm{V}$ inhibitor developing in a patient with esophageal squamous cell carcinoma. Blood Coagul Fibrinolysis. 2013; 24: 97-99.

34. Kang, Steven $\mathrm{H}$, Joseph M. Factor V Inhibitor with Complete Correction of the PT and aPTT Mixing Study. American Journal of Clinical Pathology. 2013; 140: A192.

35. Ashizawa $M$, Kimura $S$, Wada $H$, Sakamoto $K$, Sato $M$, Terasako $K$, et al. Acquired factor $\mathrm{V}$ inhibitor associated with life-threatening bleeding and a mixing test result that indicated coagulation factor deficiency. Hematology (amsterdam, Netherlands). 2013; 18: 300-304.

36. Khalafallah A, Grabek J, Hayes R, Mohamed M. Bleeding associated with acquired factor $\mathrm{V}$ inhibitor in a patient on warfarin treated successfully with prednisolone. Bmj Case Reports. 2013; 2013.

37. Sosa IR, Ellery P, Mast A, Neff AT, Gailani D. Acquired factor V deficiency in a patient without evidence of a classical inhibitor. Haemophilia : the Official Journal of the World Federation of Hemophilia. 2014; 20: 81-83.

38. Yamada $Y$, Miyakawa $Y$, Sawano M, Okano $Y$. Successful treatment of severe lung hemorrhage caused by acquired factor $V$ inhibitor with rituximab. Intern Med. 2014; 53: 1083-1085.

39. Siekanska-Cholewa A, Jarosz A, Góralczyk T, Iwaniec T, Wegrzyn W, Drwila $\mathrm{R}$, et al. Acquired factor $\mathrm{V}$ inhibitor in a woman following aortic aneurysm surgery. Blood Coagul Fibrinolysis. 2014; 25: 515-517.

40. Van BSA, Verwer PE, Idema RN, Van GC. Transient cefuroxime/ metronidazole treatment induced factor $\mathrm{V}$ antibodies. Bmj Case Reports. $2014 ; 2014$.

41. Sun LY, Zhu ZJ, Zeng ZG, Qu W, Zhang L, Tian MS, et al. Acquired factor $\checkmark$ inhibitor after liver transplantation. Clin Res Hepatol Gastroenterol. 2014; 38: 65-67.

42. Sekiguchi $Y$, Yoshikawa $H$, Shimada A, Imai $H$, Wakabayashi M, Sugimoto $K$ et al. Acquired Factor $V$ Inhibitor Developing after Treatment with Dabigatran Etexilate Methanesulfonate: A Case Report and Review of the Literature. Indian J Hematol Blood Transfus. 2014; 30: 275-279.

43. Kinjo Y, Yoshimura K, Suzuki T, Shinozawa K, Nakasone K, Yoshimata $\mathrm{T}$, et al. Development of asymptomatic acquired factor $\mathrm{V}$ inhibitor after the administration of antibiotics. [rinsho Ketsueki] the Japanese Journal of Clinical Hematology. 2014; 55: 2311-2315.

44. AlJohani N, Matthews J. Acquired factor $\mathrm{V}$ inhibitor in a patient with mantle cell lymphoma presenting with hematuria followed by thrombosis: a case report. Int Med Case Rep J. 2014; 7: 27-30.

45. Hervent AS, Schepens M, Bourgeois M, Emmerechts J. Acquired thrombin and FV inhibitors upon aortic bioprosthetic valve replacement. Haemophilia: the Official Journal of the World Federation of Hemophilia. 2014; 20: 354-356.

46. Schmid DE, Steinhagen F, Schnabel C, Spath B, Holstein K, Fiedler W, et al Thrombin generation in a patient with an acquired high-titre factor $\mathrm{V}$ inhibitor. Blood Coagul Fibrinolysis. 2015; 26: 81-87.

47. Cui QY, Shen HS, Wu TQ, Chen HF, Yu ZQ, Wang ZY Development of acquired factor $V$ inhibitor after treatment with ceftazidime: a case report and review of the literature. Drug Des Devel Ther. 2015; 9: 2395-2398.

48. Leung AK, Ng GW, Sin KC, Au SY, Lai KY, Lee KL, et al. Acquired factor $\checkmark$ inhibitor in a patient receiving venous-venous extracorporeal membrane oxygenation for Legionella pneumonia. Hong Kong Med J. 2015; 2: 175-178.

49. Ma ES, Liang RH, Chu KM, Lau GK. Complete response of acquired FV 
inhibitor to rituximab. Int J Hematol. 2015; 101: 421-422.

50. Rief P, Hackl G, Hafner F, Raggam R B, Wölfler A, Brodmann M, et al. Venous thromboembolism in a patient with persistent inhibitor to coagulation factor V - a case report. Clinical Chemistry and Laboratory Medicine. 2016; 54: $269-271$

51. Hirai D, Yamashita Y, Masunaga N, Katsura T, Akao M, Okuno Y, et al Acquired Factor V Inhibitor. Intern Med. 2016; 55: 3039-3042.

52. Cadamuro J, Skocic M, Meisl B, Raggam R B, Felder T K, Prüller F, et al. A diagnostic algorithm for the detection of inhibitors against coagulation Factor V. Clinical Chemistry and Laboratory Medicine. 2016; 54: 203-206.

53. Olson N J, Robert D, Hedayat A A, Liu X, Ornstein D L. Fatal hemorrhage due to a spontaneous factor $\mathrm{V}$ inhibitor with lupus anticoagulant properties. Blood Coagul Fibrinolysis. 2016; 1.
54. Gavva C, Yates SG, Rambally S, Sarode R. Transfusion management of factor $V$ deficiency: three case reports and review of the literature. Transfusion. 2016; 56: 1745-1749.

55. Wang X, Qin X, Yu Y, Wang R, Liu X, Ji M, et al. Acquired factor V deficiency in a patient with a urinary tract infection presenting with haematuria followed by multiple haemorrhages with an extremely low level of factor $\mathrm{V}$ inhibitor: a case report and review of the literature. Blood Coagu Fibrinolysis. 2016.

56. Cortier D, Van D P, Adam M, Bironien R, François D, Vasse M. Transient Factor $\mathrm{V}$ deficiency associated with Factor $\mathrm{V}$-immunoglobulin complexes but without evidence of a classical inhibitor. Thrombosis Research. 2016; 147: 10-12.
Ann Hematol Oncol - Volume 4 Issue 9 - 2017

ISSN : 2375-7965 | www.austinpublishing group.com Boland et al. (C) All rights are reserved
Citation: Boland F and Shreenivas AV. Acquired Factor V Inhibitors: A Review of Literature. Ann Hematol Oncol. 2017; 4(9): 1168 